(4) Control by a public authority of the manufacture and selling of hang-gliders, which should be licensed (at present any manufacturer can produce them).

(5) The mandatory use of altimeters and air-speed indicators.

(6) Designation of flying areas with favourable launching and landing sites.

(7) Avoidance of flying between 11 am and $3 \mathrm{pm}$ on hot days, when dangerous convection currents are likely.

(8) The establishment of a central information office to collect facts and figures about accidents so that safety precautions can be formulated.

Even with proper safety precautions accidents will inevitably occur, and full insurance cover should be compulsory. In our series even experienced pilots following all the rules had accidents caused by unforeseen turbulence, and we believe that hang-gliding will remain a dangerous sport.

\section{References}

${ }^{1}$ Eiseman, B, fournal of the American Medical Association, 1975, 233, 171.

2 Krissoff, W B, and Eiseman, B, fournal of the American Medical Association, 1975, 233, 158

${ }^{3}$ Yuill, G M, British Medical fournal, 1977, 1, 823.

\title{
Possible role of antibody specific for a practolol metabolite in the pathogenesis of oculomucocutaneous syndrome
}

\author{
H E AMOS, B G LAKE, J ARTIS
}

British Medical fournal, 1978, 1, 402-407

\begin{abstract}
Summary and conclusions
The clinical distribution of an antibody to a metabolite of practolol was investigated, particularly in relation to the oculomucocutaneous syndrome. Serum samples were obtained from patients with and without a history of adverse reaction to practolol and two groups of control patients who had never taken the drug. Five patients also participated in a challenge study.

The presence of the antibody was found to be related to practolol administration, and antibody activity could be increased by antigenic challenge. The role of this antibody in the pathogenesis of the oculomucocutaneous syndrome remains uncertain. The lesions may be the result of a hitherto unknown type of hypersensitivity response to practolol.
\end{abstract}

\section{Introduction}

The serious adverse effects associated with practolol are perhaps the biggest single medical tragedy since the thalidomide disaster and they emphasise the problem of assessing drugs for unexpected untoward reactions. Extensive epidemiological studies have shown that the tissue damage associated with practolol is probably confined to this one drug and is not seen in patients receiving other beta-blocking agents. The pathology of the lesions, however, is unusual for a drug-induced adverse effect, and the available data do not explain their pathogenesis. Further data are needed to clarify the pathological processes. The experimental effort necessary for such investigations is justifiable, if only to establish that the adverse responses are related to the molecular structure of practolol rather than to its specific pharmacological and therapeutic actions.

The British Industrial Biological Research Association, Carshalton, Surrey SM5 4DS

H E AMOS, MB, FIBIOL, immunologist

B G I.AKE, BSC, PHD, scientific officer

J ARTIS, BSC, HNC, research assistant
We have described a method for detecting an antibody with specificity for a phase-one metabolite of practolol, ${ }^{1}$ and this paper concerns the clinical distribution of the antibody, particularly in relation to the so-called oculomucocutaneous syndrome.

\section{Patients and methods}

Serum samples for the investigation were obtained from four groups of patients.

Group 1-This group comprised 24 patients who had taken practolol for various periods and developed some type of adverse effect. Most had conjunctival signs (as assessed by Mr P Wright, Moorfields Eye Hospital). Also included were four patients with sclerosing peritonitis that had been confirmed by laparotomy.

Group 2-This group of 15 patients had also been treated with practolol, but when serum samples were taken they had no adverse signs or symptoms attributable to their treatment.

Group 3-These 10 patients were being treated with either propanolol or atenolol and were free from any untoward effects of the drugs.

Group 4-Two control groups of patients were included in the study: (a) 10 patients who were matched so far as possible for age and physical disability with those in group 1 , but had not been treated with practolol or any beta-blocking drug; and $(b) 11$ patients with unrelated diseases such as pemphigus, pemphigoid, and systemic lupus erythematosus.

\section{DETECTION OF SERUM ANTIBODY}

Production of antigenic determinants-The antigen was derived by metabolising practolol in vitro using a microsomal mixed-function oxidase system. ${ }^{1}$ For this series of experiments hamster-liver microsomes were used, and ${ }^{125}$ I-labelled human serum albumin (HSA) was added to the microsomal incubation mixture; the generated metabolites combine spontaneously with the labelled albumin preparation. We are still investigating the detailed kinetics of metabolite production and type of macromolecular binding as well as the molecular structure of the metabolites. Two antigen controls were used, one omitted essential cofactors from the microsomal incubation mixture and the other omitted practolol until the microsomal incubations ended.

Antibody assay-A modification of the technique described by Farr'2 was used. The HSA-metabolite complex was freed from unmetabolised drug and uncoupled metabolites by Sephadex G-25 chromatography and then added to dilutions of sera from patients in the four groups. Complexes of HSA metabolite were precipitated by antibody specific for the metabolite in the presence of saturated 
ammonium sulphate. The percentage of antigen precipitated by various dilutions of antibody was calculated and the amount of antigen specifically bound to antibody determined.

\section{Results}

Figure 1 shows that the percentage of antigen precipitated by the metabolite-specific antibody in group 1 decreased as the antibody was diluted. Neither of the two antigen control preparations reacted with the serum antibodies.

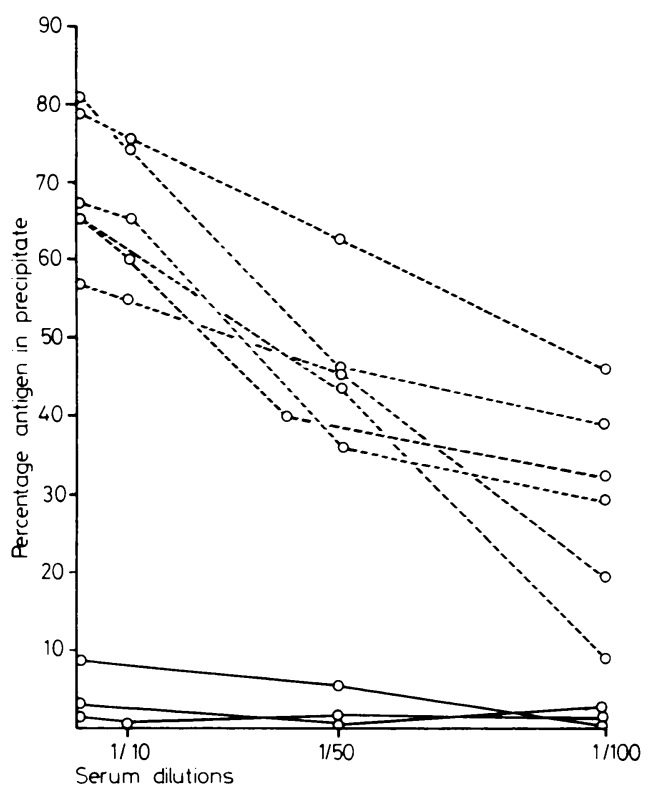

FIG 1-Antibody-binding curves for serum samples taken from patients with history of adverse reaction to practolol (group 1). Dashed line indicates sera tested against generated practolol metabolite; black line indicates sera tested against antigen controls.

There was a wide distribution of antibody activity in patients from group 1, but all sera precipitated more than $10^{\circ}{ }_{0}$ of the antigen (fig 2). None of the sera tested from patients in group 3 or from the control groups could precipitate more than $10 \%$ of the antigen and were therefore considered to lack specific antibody. Some patients in the second test group (patients treated with practolol without adverse effects) had antibodies specific for metabolites. Practolol has since been withdrawn from all these patients, and possible development of adverse effects is being monitored.

We tried to investigate the relation of concentrations of circulating antibody to the severity of the clinical signs or to the production of autoantibodies. Unfortunately, we could not draw any definite conclusions from the available information. The presence of antibody was not related to any particular expression of the oculomucocutaneous syndrome, but patients with high titres of epidermal intracellular autoantibody had low concentrations of antibody specific for metabolites. The four patients with sclerosing peritonitis also had low concentrations of circulating metabolite antibody.

We obtained serum samples from five patients who had experienced an adverse effect from practolol but were willing to undergo a challenge study with the drug. The study was approved by the ethical committee of Northwick Park Hospital. The protocol for the challenge study called for each patient to take $100 \mathrm{mg}$ practolol twice daily for one week. Serum samples were taken before and after challenge. We examined these samples for metabolite-specific antibodies. Samples were obtained for three of the patients at the height of the adverse response; the analysis is shown in the table. The results showed that in three patients (cases 1, 3, and 5) antibody activity decreased appreciably in the interval between the first sampling (at the height of the reaction) and the second (pre-challenge). The patients had been taken off the drug, however, and antibody titres fall when the antigenic stimulus is removed. When the drug had been reintroduced the antibody titre rose, as would be expected in a secondary allergic response. The adverse reaction was exacerbated in only one of the challenged patients (case 4). In this case, antibody activity was high in the pre-challenge serum sample, and did not rise greatly when the antigenic stimulus was increased.

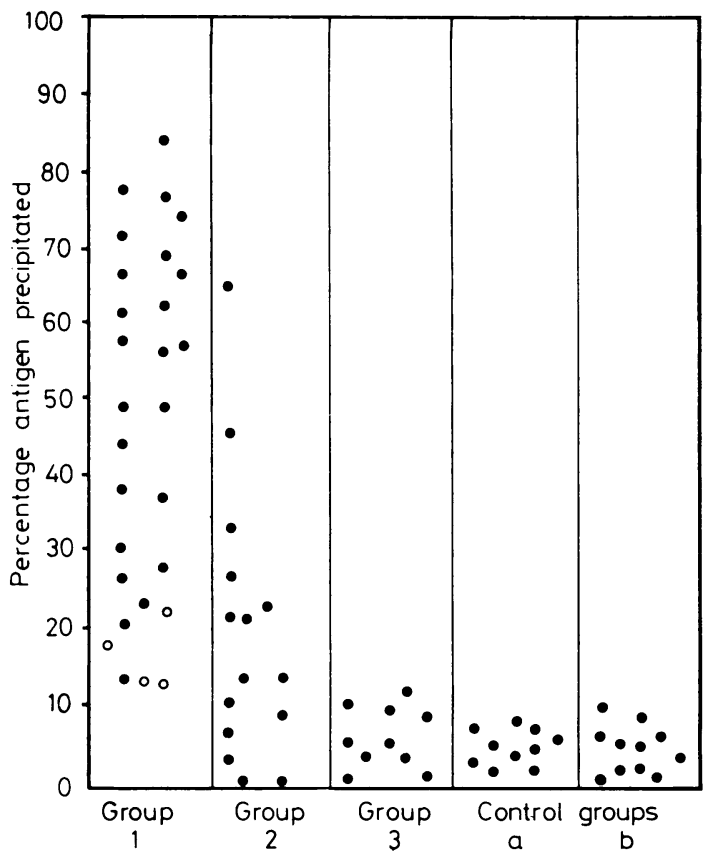

FIG 2-Scatter diagram of test and control sera tested against the generated metabolite antigen (1/10 dilutions of serum used). Open circles represent patients with sclerosing peritonitis.

Antibody activity in serum samples from patients with history of adverse reaction to practolol who were subsequently challenged with the drug. Figures are percentages of metabolite antigen precipitated by sera

\begin{tabular}{|c|c|c|c|c|c|}
\hline \multirow{2}{*}{$\begin{array}{c}\text { Case } \\
\text { No }\end{array}$} & \multirow{2}{*}{$\begin{array}{c}\text { Date of } \\
\text { sampling }\end{array}$} & \multirow{2}{*}{$\begin{array}{c}\text { Type } \\
\text { of } \\
\text { sample* }\end{array}$} & \multicolumn{3}{|c|}{ Serum dilutions } \\
\hline & & & 110 & $1 / 50$ & $1 / 100$ \\
\hline 1$\}$ & $\begin{array}{l}26 \text { March } 75 \\
10 \text { March } 76 \\
17 \text { March } 76\end{array}$ & $\begin{array}{l}\mathrm{A} \\
\mathrm{B} \\
\mathrm{C}\end{array}$ & $\begin{array}{l}77 \\
26 \\
74\end{array}$ & $\begin{array}{l}64 \\
15 \\
70\end{array}$ & $\begin{array}{l}46 \\
10 \\
63\end{array}$ \\
\hline & $\begin{array}{l}24 \text { Feb } 76 \\
3 \text { March } 76\end{array}$ & $\stackrel{\mathrm{B}}{\mathrm{C}}$ & $\begin{array}{l}8 \cdot 6 \\
67\end{array}$ & $\begin{array}{l}8 \cdot 5 \\
37\end{array}$ & $\begin{array}{l}3 \cdot 4 \\
30\end{array}$ \\
\hline 3 & $\begin{array}{c}18 \text { May } 75 \\
30 \text { March } 76 \\
7 \text { April } 76\end{array}$ & $\begin{array}{l}\text { A } \\
\text { B } \\
\text { C }\end{array}$ & $\begin{array}{l}46 \\
10 \\
43\end{array}$ & $\begin{array}{l}30 \\
8 \cdot 6 \\
35\end{array}$ & $\begin{array}{l}25 \\
6 \cdot 3 \\
21\end{array}$ \\
\hline 4 & $\begin{array}{l}20 \text { April } 76 \\
23 \text { April } 76\end{array}$ & $\stackrel{\mathrm{B}}{\mathrm{C}}$ & $\begin{array}{l}71 \\
47\end{array}$ & $\begin{array}{l}23 \\
37\end{array}$ & $\begin{array}{l}27 \\
27\end{array}$ \\
\hline 5 & $\begin{array}{l}9 \text { May } 75 \\
22 \text { Feb } 76 \\
29 \text { Feb } 76\end{array}$ & $\begin{array}{l}\mathrm{A} \\
\mathrm{B} \\
\mathrm{C}\end{array}$ & $\begin{array}{l}60 \\
13 \\
71\end{array}$ & $\begin{array}{l}41 \\
7 \cdot 6 \\
26\end{array}$ & $\begin{array}{l}36 \\
6 \cdot 4 \\
32\end{array}$ \\
\hline
\end{tabular}

${ }^{*} \mathrm{~A}=$ Treatment with practolol continuing or recently withdrawn. $\mathrm{B}=$ Practolol withdrawn from date $(\mathrm{A})$; pre-challenge sample. $\mathrm{C}=$ Post-challenge sample.

\section{Discussion}

Antibody to a drug or a drug metabolite in patients with tissue damage induced by that drug may not necessarily be the cause of the reaction. Nevertheless, practolol is a special case, and any positive piece of evidence should be examined with an open mind. The pathology of practolol-induced lesions is unique and not of a type commonly associated with hypersensitivity responses. The acceptance of what is hypersensitivity tissue damage has been largely governed by the classic descriptions of types I-IV reactions described by Coombs and Gell ${ }^{3}$ and, admittedly, practolol lesions do not readily fit into this classification; however, this does not exclude the possibility 
that the lesion may be the result of a hitherto unknown type of hypersensitivity response.

Our results do not show that the adverse effects of practolol are due to a hypersensitivity reaction, but two pieces of evidence might tentatively support such a conclusion. The first is the low antibody concentrations found in the sera of patients with sclerosing peritonitis. This might have been due to a reduction in antigenic stimuli, since the patients had been taken off the drug some time before the clinical signs of intestinal obstruction appeared. Equally, however, the results could be explained by postulating that the antigenic metabolite is incorporated into connective tissue and the mass of antigenic determinants presented by the peritoneum is sufficient to fix most of the circulating antibody. The second piece of evidence is perhaps more pertinent and concerns the challenge study on one of the patients (case 4). This patient had high concentrations of circulating antibody before challenge with practolol, and when the drug was given, clinical signs of the tissue damage were produced. Other patients in the study might have shown an adverse response if the drug had been given for a longer period.
Continued analysis of serum will probably provide only circumstantial evidence of a practolol-induced hypersensitivity reaction. An animal model is needed to study the tissue damage produced by the drug, and we are currently engaged in studies $\underline{\underline{T}}$ of this kind.

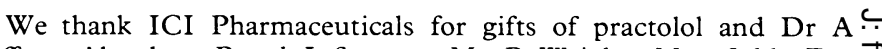
Jeffers, Aberdeen Royal Infirmary, Mr P Wright, Moorfields Eye Hospital, Dr F J Zacharias, Clatterbridge Hospital, and Dr S Pugh, Northwick Park Hospital, for providing serum samples.

\section{References}

${ }^{1}$ Amos, H F, Lake, B G, and Atkinson, H A C, Clinical Allergy, 1977, 7, 243.

2 Farr, R S, Fournal of Infectious Diseases, 1958, 103, 239.

Coombs, R R A, and Gell, P H G, in Clinical Aspects of Immunology, ed $\vec{\omega}$ P H G Gell and R R A Coombs. Oxford, Blackwell, 1963.

\title{
Diabetic cardiomyopathy? An echocardiographic study of young diabetics
}

\author{
J E SANDERSON, D J BROWN, A RIVELLESE, E KOHNER
}

British Medical fournal, 1978, 1, 404-407

\section{Summary and conclusions}

An echocardiographic study was carried out on 23 young diabetics, 19 of whom had retinopathy. Their diastolic function was analysed by comparing the timing and pattern of mitral valve opening with the pattern of left ventricular wall movement. Only six patients had all their values within the normal range. Fourteen patients had abnormalities similar to those seen in patients with cardiomyopathy; the close time relation between mitral valve movement and wall movement was lost and mitral valve opening delayed in eight patients. Three other patients had considerable outward wall movement before mitral valve opening, which is characteristic of ischaemic heart disease.

Although these studies provide no definite evidence of a cause, the abnormalities found may reflect a subclinical diabetic cardiomyopathy due to small-vessel disease.

\section{Introduction}

Accelerated coronary artery disease is a well-known feature of diabetes mellitus and it accounts for much of the morbidity and mortality of this condition. Several reports, ${ }^{1-3}$ however, have noted that congestive heart failure and cardiomegaly occur in

\footnotetext{
Hammersmith Hospital, London W12 0HS

J E SANDERSON, MA, MRCP, research fellow, department of clinical cardiology

A RIVELLESE, MD, research fellow, department of endocrinology

E KOHNER, MD, FRCP, senior lecturer, department of endocrinology

Cardiac Department, Brompton Hospital, London SW3

D J BROWN, BSC, MA, computer systems designer
}

diabetics with normal coronary arteries. At necropsy ${ }^{23}$ and in myocardial biopsy specimens ${ }^{1}$ small-vessel changes and diffuse $\overline{0}$

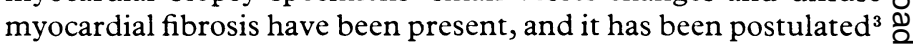
that a diabetic microangiopathy may cause this heart-muscle $\mathbb{\mathscr { Q }}$ disease or cardiomyopathy. ${ }^{2}$

Echocardiographic studies in healthy people have shown that diastole is a co-ordinated and precisely timed process. Relaxation $\vec{\partial}$ of the left ventricle and the consequent filling is reflected in the outward wall movement seen echocardiographically, ${ }^{4}$ and this movement is closely related to movement of the mitral valve, both events showing an identical pattern of movement. ${ }^{5}$. Disturbance of the close relation between left ventricular wall $\frac{0}{3}$ movement and mitral valve movement seems to be a sensitive index of a myocardial abnormality, and abnormalities have been $\frac{0}{3}$ shown in both ischaemic heart disease ${ }^{5}$ and hypertrophic cardiomyopathy. ${ }^{\circ}$; We therefore decided to perform echo- $\frac{0}{7}$ cardiographic studies to assess the myocardial function of young $\mathbb{\sim}$ diabetics. None had any clinical evidence of ischaemic heart $D$ disease, though most had retinopathy and therefore evidence of small-vessel disease. We also studied the beat-to-beat variation $N$ in heart rate as an indication of autonomic neuropathy affecting N the heart. ${ }^{8}$

\section{Patients and methods}

Echocardiographic studies were performed on 32 diabetics aged under 40 , but the records of only 23 were of sufficiently high standard $\stackrel{\mathbb{D}}{D}$ for further analysis. The mean age of these 23 patients (12 women) was 31 years (15-39 years). They had had diabetes for a mean of 17 years (2-28 years). All patients had normal blood pressure, were in sinus rhythm, and had no clinical evidence of heart disease. 8 Sixteen patients had proliferative retinopathy, which was florid in one; three patients had background retinopathy and four had normal eyes. In 20 of these patients the beat-to-beat variation was also studied. All patients had a normal chest radiograph and electrocardiogram. Fifteen healthy subjects of the same age and sex distribution were also studied echocardiographically, and 18 healthy subjects had their beatto-beat variation measured. 